DOI: $10.5455 / 2320-1770.1 j \operatorname{cog} 20141252$

\title{
A rare case of congenital vesico-uterine fistula
}

\author{
Parul Sinha $^{1,2 *}$, Nisha Rani Agrawal ${ }^{1}$ \\ ${ }^{1}$ Department of Obstetrics \& Gynecology, IMS, BHU, Varanasi, U.P, India \\ ${ }^{2}$ Department of Obstetrics \& Gynecology, Era's Lucknow Medical College, Lucknow, U.P, India
}

Received: 8 September 2014

Accepted: 19 September 2014

\section{*Correspondence:}

Dr. Parul Sinha,

E-mail: drparulanand@gmail.com

Copyright: $\odot$ the author(s), publisher and licensee Medip Academy. This is an open-access article distributed under the terms of the Creative Commons Attribution Non-Commercial License, which permits unrestricted non-commercial use, distribution, and reproduction in any medium, provided the original work is properly cited.

\begin{abstract}
Herein we report the case of a patient with primary amenorrhea and cyclical menouria. The patient was a 20 years female with primary amenorrhea. Clinical examination revealed normal external genitilia. A mature female pubic hair pattern was present, and axillary development was normal. Breast was normally developed. Intraoperatively, a congenital vesico-uterine fistulous tract was observed. Repair was done. The patient has been regularly menstruating since the operation.
\end{abstract}

Keywords: Primary amenorrhea, Menouria, Vesico-uterine fistula

\section{INTRODUCTION}

The term Menouria was coined by Youssef $^{1}$ to describe the most important presenting sign of a syndrome - i.e. vesical menstruation, due to a vesico-uterine fistula and characterized by absence of urinary incontinence and absence of vaginal bleeding. Twelve cases, recorded in literature, followed some complication of pregnancy. Lower segment cesarean section was responsible for 11 of them and 1 case developed after the sloughing into bladder of a rubber catheter placed in the uterus for inducing an abortion.

\section{CASE REPORT}

40 years old nulliparous female presented in emergency with the complaints of abnormal passage of menstrual blood through urinary tract and dysmenorrhea since menarche, severe crampy abdominal pain for 2 years, painful micturition for 2 days. Her previous cycles were regular. She achieved menarche at the age of 14 years, which occurred through the urinary tract, was associated with severe pain in the perineum. She got married at the age of 18 years. Her vaginoplasty was done at the age of 20 years. She had a past history of appendicectomy done
2 years back. She presented in emergency with severe pain in the suprapubic region for 2 days. On examination, her pulse was $82 / \mathrm{mt}$., regular; B.P. was $116 / 60 \mathrm{~mm}$ of $\mathrm{Hg}$, afebrile. On abdominal examination, guarding was present. On $\mathrm{p} / \mathrm{s}$ examination blind vagina was seen. On $\mathrm{P} / \mathrm{V}$ examination, vagina was $3 \mathrm{~cm}$ long. On $\mathrm{P} / \mathrm{R}$ examination, uterus was enlarged equivalent to 10 weeks. The patient was sent to the urosurgeon for reviewing the case and opining their views. They suggested the diagnosis of utero-vesical fistula and advised cystoscopy. On investigations her USG showed absent right kidney, ectopic insertion of left ureter, bulky uterus with heterogenous myometrium with poor definition of endometrium, nodularity noted in the cervical region. Her cystoscopy report revealed $0.5 \times 1 \mathrm{~cm}$ opening with marginal hyperemic growth near right lateral wall near end of trigone? utero-vesical fistula?? congenital anomaly. Right uretric orifice was not seen, left uretric orifice not visualized due to trigonal edema. She was planned for exploratory laparotomy with the assistance of urosurgeons.

On opening the abdomen, dense adhesions were present between bowel and uterus, which were dissected. Bladder was also adhered to the uterus. Posterior wall of the 
urinary bladder was separated from the uterus. On dissection of left ureter, it was dilated till its lower end, presumably because of pressure effects. A fistula of about $2 \times 2 \mathrm{~cm}$ size was seen in the posterior wall of uterus. Her total abdominal hysterectomy was done, the urinary bladder was bivalved through the fistula. Left uretric orifice was cannulated and was found to be lying below its normal position. Left D-J stenting was done and bivalved was closed in 2 layers. A suprapubic catheter was put and per urethral catheter was secured. A drain was put in the perivesical region and abdomen was closed. The catheters were advised to be put for 3 weeks. Her post-operative period was uneventful. She was discharged on the $22^{\text {nd }}$ post-operative day in healthy condition. Since then the patient has been in regular follow-up and presently has no complaints.

\section{DISCUSSION}

The literature includes 3 other reports cases of primary menouria. Whittemore ${ }^{2}$ described a patient with vaginal agenesis, unicornuate uterus, a vesicocervical communication and agenesis of the left kidney, who after surgical correction, conceived and was delivered by cesarean section. Sicard ${ }^{3}$ described a patient with agenesis of the rectum and vagina and with a vesicouterine communication.

Insufficient differentiation of the urogenital sinus affords an explanation for the absence of the distal part of the vagina. Experimental agenesis of the lower end of the vagina also produces an abnormal persistence of the urogenital sinus. ${ }^{4}$ Persistence of the urogenital sinus in the female represents an abnormal closure with a relatively superior position of the vagina. This fact is better appreciated when it is remembered that in the male urogenital tract the level of vaginal development would be represented by the prostatic utricle. The surgically significant malformations of urogenital sinus are: urinary incontinence, double vagina, blind sacs, the small caliber of the sinus and the associated urinary tract and skeletal disorders. ${ }^{5}$ In the very young baby the urogenital sinus is only a fraction larger than the normal adult urethra. Two postnatal processes may occur. First the sinus may continue to replicate, bringing the urethra and vaginal orifices closer to the exterior. Second, the sinus may undergo considerable expansion at the time of puberty and the caliber approach that of a normal vagina. Therefore treatment should be withheld until after puberty. The absence of right kidney support the need for proper functional and anatomic evaluation of the urinary tract, since the incidence of urinary tract malformations associated with absence of vagina is very high.

Absence of the distal vagina can be discovered at the time the newborn infant is examined, and diagnosis probably will be vaginal agenesis. When a buccal smear shows chromatin bodies, in a 7 or 8 year old, further diagnostic procedures such as laparoscopy should be advised. Anomalies of the vagina are not symptomatic during infancy and childhood and rarely disturb older girls unless they interfere with or prevent menstruation.

As yet the long term effects of the continuous diversion of the menstrual blood to the bladder are unknown because these patients are operated soon after the discovery of their monthly hematuria but it may cause papillitis of the calyces leading to recurrent urinary tract infections.

\section{Funding: No funding sources \\ Conflict of interest: None declared \\ Ethical approval: Not required}

\section{REFERENCES}

1. Youssef AF. "Menouria" following lower segment cesarean section: a syndrome. Am J Obstet Gynaecol. 1957;73:759-67.

2. Whittemore WS. Pregnancy following operation for congenital absence of vagina. Am J Obstet Gynaecol. 1942;44:516-21.

3. Sicard A. Absence congenitale du vagin et du rectum. Memoirs de l'Academic de cherugi. 1949;75:444-6.

4. Wells LJ. Vaginal anatomy and physiology. Ann NY Acad Sci. 1959;83:80-8.

5. Stephens FD. Urethro-vaginal malformations. Aust NZ J Obstet Gynaecol. 1966;5:64-73.

DOI: $10.5455 / 2320-1770 . i j \operatorname{rog} 20141252$

Cite this article as: Sinha P, Agrawal NR. A rare case of congenital vesico-uterine fistula. Int J Reprod Contracept Obstet Gynecol 2014;3:1125-6. 